\title{
Commentary on: "Vertebral Artery Anomalies at the Craniovertebral Junction: A Case Report and Review of the Literature"
}

\author{
Robert W. Molinari ${ }^{1}$ \\ ${ }^{1}$ Department of Orthopaedic Surgery, University of Rochester Spine \\ Center, Rochester, New York, United States \\ Evid Based Spine Care J 2014;5:126.
}

The authors report a case of an unstable $\mathrm{C} 1$ fracture with magnetic resonance imaging demonstrating rupture of the transverse ligament. Posterior vertebral artery anomaly in the form of a right persistent first intersegmental artery was identified preoperatively in the region of the right posterior C1-C2 lateral mass interval. The surgical plan was altered to avoid the anomalous vertebral artery and the patient was successfully managed with an uncomplicated occiput to C3 instrumentation and fusion procedure. The literature review includes a discussion of the work by Uchino et al who have reported a persistent first intersegmental artery in up to $3.2 \%$ of normal subjects and an overall prevalence of craniovertebral junction vertebral artery anomalies of $5 \%{ }^{1}$

This article is an important addition to the existing literature as it highlights the relatively high prevalence of vertebral artery anomalies at the craniovertebral junction. The case described involves an aberrant vertebral artery with an anomalous course located posteriorly between the $\mathrm{C} 1$ and C2 lateral masses. This particular vertebral artery anomaly poses great risk to the conventional placement of $\mathrm{C} 1$ lateral mass screws through previously described techniques involving the exposure of the $\mathrm{C} 1$ lateral mass or placement of the screw through the $\mathrm{C} 1$ posterior ring. The anomaly was identified preoperatively by computed tomography angiography in this case, and intraoperative vertebral artery injury was avoided. The utility of the use of routine of preoperative imaging studies to demonstrate the course of the bilateral vertebral arteries before any planned exposure of the craniocervical junction is clearly implied in this case report.

The significance of this case report and review of the literature lies in the identification of the increased risk of complication involving vertebral artery injury through a routine posterior cervical spine surgical exposure. Much of the existing literature involving vertebral artery injury in cervical spinal surgery has focused on injuries incurred with
Address for correspondence Robert W. Molinari, MD, Department of Orthopaedic Surgery, University of Rochester Spine Center, 601 Elmwood Avenue, Box 665, Rochester, NY 14642 (e-mail: bobmol@aol.com).

anterior cervical spinal surgical procedures. Tortuous anterior course of the vertebral artery in the subaxial cervical spine has been well described by Curylo et al in approximately 5.5\% of subjects. ${ }^{2}$ Multiple reports of injury to the vertebral artery during anterior cervical decompression surgery exist in the literature. $^{3}$ Five studies reported rates of 0.10 to $1.96 \%$, depending on the type of anterior cervical spine procedure. ${ }^{3}$ There remains, however, a paucity of literature with respect to vertebral artery injury incurred with a posterior cervical surgical exposure. Molinari et al recently reported vertebral artery injury in two cases involving a persistent first intersegmental artery in the region of $\mathrm{C} 1-\mathrm{C} 2$. Both injuries were incurred with routine posterior exposure of the $\mathrm{C} 1-\mathrm{C} 2$ anatomy. A review of the existing literature demonstrates few publications on this topic. $^{3}$

The authors should be applauded for this work, which raises a greater sense of awareness as to the increased potential for vertebral artery injury during posterior cervical spine exposure in the region of the craniocervical junction. Their work underscores the need for thorough preoperative evaluation of the course of the vertebral artery before performing operative procedures on the cervical spine.

\section{References}

1 Uchino A, Saito N, Watadani T, et al. Vertebral artery variations at the C1-2 level diagnosed by magnetic resonance angiography. Neuroradiology 2012;54(1):19-23

2 Curylo LJ, Mason HC, Bohlman HH, Yoo JU. Tortuous course of the vertebral artery and anterior cervical decompression: a cadaveric and clinical case study. Spine (Phila Pa 1976) 2000;25(22): 2860-2864

3 Molinari R, Bessette M, Raich AL, Dettori JR, Molinari C. Vertebral artery anomaly and injury in spinal surgery. Evid Based Spine Care J 2014;5(1):16-27 received

June 2, 2014

accepted

June 2, 2014 (c) 2014 Georg Thieme Verlag KG Stuttgart · New York
DOI http://dx.doi.org/ 10.1055/s-0034-1386757. ISSN 1663-7976. 